\title{
Do outside temperature and sunlight duration influence the outcome of laser refractive surgery? Results from the Hamburg Weather Study
}

This article was published in the following Dove Press journal:

Clinical Ophthalmology

13 June 2014

Number of times this article has been viewed

\author{
Ines Neuhaus-Richard' \\ Andreas Frings ${ }^{\prime}$ \\ Isabel Caroline Görsch' \\ Vasyl Druchkiv' \\ Toam Katz ${ }^{1,2}$ \\ Stephan Johannes Linke ${ }^{1,2}$ \\ Gisbert Richard' \\ 'Department of Ophthalmology, \\ University Medical Center \\ Hamburg-Eppendorf, ${ }^{2}$ Care Vision \\ Refractive Centers, University \\ Medical Center Hamburg-Eppendorf, \\ Hamburg, Germany
}

Purpose: To examine the impact of temperature and sunlight duration on refractive and visual outcome of laser-assisted in situ keratomileusis (LASIK) in myopic eyes.

Setting: University Medical Center Hamburg-Eppendorf, Germany, and Care Vision Refractive Centers, Germany.

Design: Retrospective, cross-sectional data analysis.

Methods: This study comprised 1,052 eyes of 1,052 consecutive myopic patients

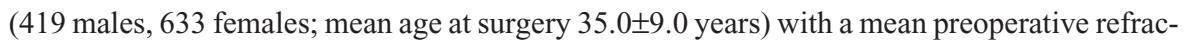
tive spherical equivalent (SE) of $-3.88 \pm 1.85$ diopters (D). Two subgroups were defined, comprising patients undergoing surgery during either meteorological winter or summer. Manifest refraction, uncorrected, and corrected distant visual acuity (UDVA and CDVA) were assessed pre- and postoperatively. We applied robust regression analysis with efficiency index (EI), safety index (SI), and postoperative SE (in D) as dependent variables.

Results: At the 1-month (33.0 \pm 5.0 days) follow-up, the mean postoperative SE was $-0.18 \pm 0.44 \mathrm{D}$. Bivariate comparisons showed that statistically significant better EI was related to days with lower temperature. We obtained a significant difference for SI which suggested that low temperature had a positive influence on SI. No change by more than one line on LogMAR scale was obtained.

Conclusion: Although being statistically significant, there was no clinically relevant difference in the outcome of LASIK, which demonstrates its highly standardized quality. Prospective, longitudinal studies are warranted to address meteorotropic reactions through evaluating defined meteorological parameters.

Keywords: temperature, sunlight, refractive surgery, weather, LASIK

\section{Introduction}

Laser-assisted in situ keratomileusis (LASIK) has become the most popular method of surgical vision correction. ${ }^{1,2}$ Minimal discomfort, rapid recovery of visual acuity, high efficacy, and a minimal wound-healing response have been described as major advantages. ${ }^{3}$ However, before undergoing LASIK, numerous factors have been established as having potential adverse effects on LASIK. ${ }^{3,4}$

Health concerns have centered on discussions about environmental factors as possible triggers for diseases. In relation to issues of health, the environment can be the most affecting factor on the causation and outcome of non-genetic diseases. ${ }^{5}$ Weather and climate are two important examples of environmental influences. ${ }^{5}$ Man is a tropical animal;,6,7 we feel most comfortable at moderate heat. ${ }^{6,8}$ This so-called meteorotropic reaction is a function of the intensity of the
Correspondence:Andreas Frings Department of Ophthalmology, University Medical Center Hamburg-Eppendorf, Martinistraße 52, Hamburg, Germany $\mathrm{Tel}+4940741052301$

Fax +494074I0 54906

Email a.frings@uke.de 
influencing factors, and of the exposure to them, as well as the individual's adaptive capability. ${ }^{9}$ Thus, the biological influence of weather, also called biotropy, can be "health-endangering". As has been previously examined, its impact is most evident on major acute cardiovascular events. ${ }^{10}$ Heat stroke has been noted as the most obvious cause of acute illness directly attributable to weather. ${ }^{11}$ The elderly population, in particular, is at a high risk of developing heat-related mortality. ${ }^{12-17}$ Death rates were reported lowest on days with maximum temperatures of approximately $20^{\circ} \mathrm{C}-25^{\circ} \mathrm{C}$ and became progressively higher with uncomfortable hot weather. ${ }^{18-20}$ Other causes of death, such as ischemic heart disease, diabetes, stroke, respiratory diseases, accidents, violence, suicide, and homicide have been observed to increase following heat waves. ${ }^{14,18,21,22}$ Contrarily, increased morbidity and mortality in colder months have been largely explained by physiological mechanisms. A lower body temperature on admission has been associated with adverse prognosis in patients with advanced chronic heart failure. ${ }^{20} \mathrm{~A}$ winter increase of the onset of acute aortic dissection has been reported by several authors. ${ }^{23}$

Besides its role in cardiovascular events, meteorotropic reaction has also been described in the field of ophthalmology. The eye can be damaged by visible light energy, as well as ultraviolet (UV), and infrared wavelengths. These diseases have been termed the ophthalmohelioses, which pose a significant problem to the eye health of many communities. ${ }^{24}$ Moreover, epidemiologic evidence has revealed age-related macular degeneration (AMD) as being associated with severity of sunlight exposure. $^{25}$

There have also been publications on the effects of individual environmental variables on the outcome of refractive surgery. Recently, Seider et $\mathrm{al}^{26}$ in a study looking at 1-month outcomes of over 200,000 eyes undergoing LASIK in the UK and Ireland between 2008 and 2011, reported no clinically significant relationship between operating room temperature and post-operative refraction. In 2004, Walter et $\mathrm{al}^{27}$ analyzed multiple environmental variables and their effect on post-myopic LASIK refraction. Interestingly, their conclusions were that 2-week preoperative mean outdoor temperature and laser room temperature all were statistically significant factors in predicting the need for enhancement.

This study was thus initiated to assess the impact of outdoor temperature and sunlight duration on the refractive and visual outcome of LASIK in myopic eyes.

\section{Patients and methods}

This study comprised 1,052 eyes of 1,052 consecutive myopic patients (419 males, 633 females; mean age at surgery $35.0 \pm 9.0$ years) with a mean preoperative refractive spherical equivalent (SE) of $-3.88 \pm 1.85 \mathrm{D}$. We examined one randomly selected eye from each patient. Exclusion criteria were ocular pathology and medication likely to influence the stability of refractive error. Patients suffering from hyperthyroidism, hypothyroidism, malignant hyperthermia, and taking psychotropic drugs, beta blockers, and drugs interfering with temperature balance were excluded from analysis. ${ }^{12}$ Diabetics with ocular manifestation were not subjected to LASIK (patients with DM type I were not treated anyway). Eyes that could not be refracted to $20 / 20$ but had no obvious pathology were included (ie, mild amblyopia).

All patients were treated between 2010 and 2012 at Care Vision Refractive Centers in Germany. All patient data was de-identified prior to analysis. Our study adhered to the tenets of the Declaration of Helsinki and was approved by the local ethics committee.

Manifest spherical and cylindrical refractions, and visual acuity with and without correction were assessed pre- and postoperatively after 1 day, and 1 and 6 months, and recorded electronically. However, all results reported herein are based on the 1-month (33.0 \pm 5.0 days) follow-up data (Table 1). All subjective refractions were acquired by expert optometrists.

The refractive outcome was analyzed according to standard graphs for reporting the results of refractive surgery, as suggested by Dupps et al. ${ }^{28}$ Our results are based on first treatments only; enhancements were not included.

\section{Geography and climate}

Germany is in Western and Central Europe. It lies mostly between latitudes $47^{\circ}$ and $55^{\circ} \mathrm{N}$, and longitudes $5^{\circ}$ and $16^{\circ} \mathrm{E}$.

Most of Germany has a temperate seasonal climate in which humid westerly winds predominate. Rainfall occurs year-round, especially in the summer. Winters are mild and summers tend to be cool, though temperatures can exceed $30^{\circ} \mathrm{Celsius}\left({ }^{\circ} \mathrm{C}\right)$.

The east has a more continental climate; central and southern Germany are transition regions which vary from moderately oceanic to continental.

\section{Definition of seasonality and treatment subgroups}

Of all myopic eyes that had undergone LASIK between January 1, 2010 and December 20, 2012, two subgroups 
Table I Descriptive statistics

\begin{tabular}{|c|c|c|c|c|c|c|}
\hline & \multicolumn{2}{|c|}{ Summer $(n=373)$} & \multicolumn{2}{|c|}{ Winter $(n=679)$} & \multicolumn{2}{|c|}{ Total $(n=I, 052)$} \\
\hline & Range & Mean (SD) & Range & Mean (SD) & Range & Mean (SD) \\
\hline Sex (male) & - & $37 \%$ & - & $41 \%$ & - & $40 \%$ \\
\hline Age (years) & $17 / 59$ & $36.06(9.14)$ & $18 / 68$ & $35.02(9.59)$ & $17 / 68$ & $35.39(9.44)$ \\
\hline Pre-op SE (D) & $-10.25 /-0.88$ & $-3.81(1.75)$ & $-10.13 /-0.63$ & $-3.92(1.9)$ & $-10.25 /-0.63$ & $-3.88(1.85)$ \\
\hline CDVA (LogMAR) & $-0.2 / 0.7$ & $-0.02(0.07)$ & $-0.2 / 0.4$ & $-0.02(0.06)$ & $-0.2 / 0.7$ & $-0.02(0.07)$ \\
\hline Temperature $\left({ }^{\circ} \mathrm{C}\right)$ & $-10.7 / 10.1$ & $2.82(4.84)$ & $10.6 / 26.6$ & $18.32(3.3)$ & $-10.7 / 26.6$ & I $2.83(8.39)$ \\
\hline Sunlight (hours) & $0 / 10.08$ & $2.11(2.87)$ & $0 / 15.15$ & $6.07(3.97)$ & $0 / 15.15$ & $4.66(4.08)$ \\
\hline Post-op SE (D) & $-1.63 / 1.38$ & $-0.16(0.4)$ & $-2.25 / 3$ & $-0.19(0.46)$ & $-2.25 / 3$ & $-0.18(0.44)$ \\
\hline El (LogMAR) & $-0.18 / 0.52$ & $0.03(0.09)$ & $-0.12 / 0.65$ & $0.05(0.12)$ & $-0.18 / 0.65$ & $0.04(0.11)$ \\
\hline SI (LogMAR) & $-0.18 / 0.2$ & $-0.01(0.05)$ & $-0.35 / 0.97$ & $-0.01(0.07)$ & $-0.35 / 0.97$ & $-0.01(0.06)$ \\
\hline
\end{tabular}

Abbreviations: CDVA, corrected distance visual acuity; El, efficiency index; SE, spherical equivalent; SI, safety index; SD, standard deviation; Pre-op, preoperative; Post-op, postoperative; D, diopter.

were defined: those who had undergone surgery during winter or summer. In this study, we applied the meteorological definition of seasons. Accordingly, winter was defined to be the three coldest calendar months. This corresponds to the months of December, January, and February in the Northern hemisphere.

Summer extends for the months of June, July, and August in the Northern hemisphere. This meteorological definition of summer also aligns with the commonly viewed notion of summer with the longest and warmest days of the year.

All climate data reported herein was retrieved electronically from the German Weather Service (Deutscher Wetterdienst [DWD]), and was systematically analyzed by an expert meteorologist (FA) from the Meteorological Institute (University of Hamburg, Germany).

The meteorological data included hourly readings and daily summaries, recorded by the meteorological stations of the German Weather Service. These stations were located in the cities of Berlin, Frankfurt, Hamburg, Hanover, Cologne, Munich, Nuremberg, and Stuttgart. Each station was located close to the Care Vision Centre, respectively.

\section{Target parameters and statistical analysis}

The following meteorological parameters were assessed.

\section{Temperature $\left({ }^{\circ} \mathrm{C}\right)$}

- Maximum temperature $\left(\mathrm{T}_{\max }\right)$

- Minimum temperature $\left(\mathrm{T}_{\min }\right)$

- Mean temperature $(\mathrm{T})$

\section{Sunlight (duration in hours)}

After the data were compiled, they were entered into a spreadsheet program (Excel; Microsoft, Redmond, WA,
USA; Hamburg Refractive Database) and were statistically analyzed using the STATA-PC program (v11.0 for Windows PC; Stata Corporation, College Station, TX, USA).

We applied regression analysis based on robust regression methods. The idea of robust regression is to weigh observations based on their leverage or deviation from prediction obtained by ordinary-least-square (OLS)-analysis. It is a form of weighted and reweighted least squares regression.

The dependent variables were efficiency index (EI) and safety index (SI), measured on the log scale, and postoperative SE (D). To describe EI and SI, the following formulas were applied:

$$
\begin{aligned}
& \mathrm{EI}=-\log 10\left(\mathrm{UCVA}_{\text {postop }}\right)+\log _{10}\left(\mathrm{CDVA}_{\text {preop }}\right) \\
& \mathrm{SI}=-\log 10\left(\mathrm{CDVA}_{\text {postop }}\right)+\log _{10}\left(\mathrm{CDVA}_{\text {preop }}\right)
\end{aligned}
$$

Efficacy was defined as the mean of the ratio of postoperative UDVA (uncorrected distance visual acuity) to preoperative CDVA (corrected distance visual acuity). Safety was defined as the mean of the ratio of postoperative CDVA to preoperative CDVA, and thus, EI or SI could be interpreted as lines gained or lost after refractive surgery. By applying the above mentioned formulas, positive results indicate a less effective treatment, while negative results indicate a more effective treatment. Therefore, negative coefficients in robust regression indicate a positive impact of the independent variable on the outcome, while this was negatively influenced by positive coefficients. Although approximately normal distribution was confirmed by analysis of residuals, we decided to apply robust regression methods instead of simple OLS-estimation to control for some minor violations of distributional assumption. 
Table 2 Cut-offs* for the grouping of independent meteorological parameters

\begin{tabular}{llll}
\hline Percentiles & 25th & 50th & 75th \\
\hline Temperature $\left({ }^{\circ} \mathrm{C}\right)$ & 5.9 & 15.5 & 19.3 \\
Sunlight (hours) & 0.683 & 4.15 & 7.767 \\
\hline
\end{tabular}

Note: $*$ Three groups were built: Ist: $\leq 25$ th percentile; 2 nd: 25 th -75 th percentile; 3rd: $\geq 75$ th percentile.

The independent variables were season (winter and summer), temperature $\left({ }^{\circ} \mathrm{C}\right)$, and sunlight (hours). In addition, we controlled for the possible confounding effect of preoperative CDVA and preoperative SE.

To assess a linear relationship between these independent variables and EI, SI, and postoperative SE, for temperature $\left({ }^{\circ} \mathrm{C}\right)$ and sunlight (hours), groups were built by applying the 25 th and 75 th percentiles, thereby defining three subgroups (Table 2). With this in view, our analyses compared EI, SI, and postoperative SE between winter and summer in general, and between independent meteorological parameters. A $P$-value of $P<0.05$ was considered statistically significant.

\section{Surgical technique}

The LASIK procedure included mechanical flap preparation using an automated microkeratome (SKB; Moria, Antony, France) and single use $90.0 \mu \mathrm{m}$ head. The excimer ablation in all eyes was done with the Allegretto excimer laser platform (Eye-Q $200 \mathrm{~Hz}$ or $400 \mathrm{~Hz}$; WaveLight GmbH, Erlangen, Germany) under constant eye tracking $(250 \mathrm{~Hz})$ using an aspherical "wavefront optimized" profile aimed at reducing the induced spherical high-order aberration with an optical zone of $6.0,6.5$, or $7.0 \mathrm{~mm}$, depending on the mesopic pupil diameter and expected residual stromal bed. ${ }^{29}$ The manufacturer recommended "WaveLight myopic astigmatic nomogram" was implemented to compensate for very short or long ablation times and for cylinder-sphere coupling effect.
Cyclotorsion was minimized using the "Neurotrack" system (WaveLight $\mathrm{GmbH}$ ): Four built-in blinking light sources eliminated cyclotorsion at its source by controlling optokinesis, a neural response of the visual system to use spatial cues to stabilize retinal images.

All laser treatments were performed by 21 experienced refractive surgeons in nine Care Vision Refractive Centers located in Berlin, Cologne, Frankfurt/Main, Hamburg, Hanover, Munich, Nuremberg, and Stuttgart. All surgeons followed a standard protocol of indications, preoperative, intraoperative, and postoperative management as written by the medical director (Dr Katz) of Care Vision, Germany, and were trained by him in situ. To rule out systematic differences between $200 \mathrm{~Hz}$ and $400 \mathrm{~Hz}$ lasers, and thus between centers as $200 \mathrm{~Hz}$ and $400 \mathrm{~Hz}$ lasers vary with different centers, the Kruskal-Wallis test has been applied elsewhere, ${ }^{30}$ indicating that there were no statistically significant differences. Additionally, one might argue that refractive centers constituted clusters and therefore, one should take a clustered nature of the data into account. We tested and ruled out this hypothesis by estimating an intra-class correlation.

Postoperative medication for LASIK included ofloxacin four times a day for 1 week and dexamethasone four times a day for the first week, and two times a day for the second and third weeks. All eyes received preservative-free hyaluronic acid artificial tears (Hylo-lasop; Ursapharm $\mathrm{GmbH}$, Saarbrücken, Germany) for 1-3 months.

\section{Results}

Table 3 summarizes EI, SI, and postoperative SE (in D) for temperature and sunlight duration as displayed by subgroups of quartiles. The cut-offs for grouping are shown in Table 2. Bivariate comparison revealed a significantly different EI between subgroups of differing temperature, as defined by quartiles. Based on our data, eyes being treated

Table $3 \mathrm{El}$, SI, and postoperative SE for independent meteorological parameters

\begin{tabular}{lllll}
\hline Percentiles & 25th & 50th & 75th & P-value* \\
\hline Temperature & & & & \\
EI & $0.03(0.097)$ & $0.051(0.11)$ & $0.04(0.11)$ & 0.034 \\
SI & $-0.019(0.05)$ & $-0.007(0.06)$ & $-0.002(0.08)$ & 0.003 \\
Post-op SE & $-0.15(0.4)$ & $0.18(0.44)$ & $-0.18(0.44)$ & 0.607 \\
Sunlight & & & & \\
El & $0.04(0.10)$ & $0.04(0.10)$ & $0.06(0.12)$ & 0.214 \\
SI & $-0.012(0.05)$ & $-0.012(0.05)$ & $-0.002(0.08)$ & 0.116 \\
Post-op SE & $-0.14(0.42)$ & $-0.19(0.42)$ & $-0.18(0.49)$ & 0.253 \\
\hline
\end{tabular}

Note: *F-statistics with robust standard errors.

Abbreviations: El, efficiency index; SE, spherical equivalent; SI, safety index; Post-op, postoperative. 
Table 4 Robust regression with El as the dependent variable

\begin{tabular}{|c|c|c|c|c|c|}
\hline \multirow[b]{2}{*}{ Season (winter) } & \multirow[t]{2}{*}{ Coefficient } & \multirow[t]{2}{*}{$t$} & \multirow[t]{2}{*}{$P$-value } & \multicolumn{2}{|c|}{$95 \%$ confidence interval } \\
\hline & & & & & \\
\hline Summer & 0.023 & 2.15 & 0.032 & 0.002 & 0.043 \\
\hline \multicolumn{6}{|l|}{ Temperature (low) } \\
\hline Moderate & -0.003 & -0.31 & 0.755 & -0.021 & 0.016 \\
\hline High & -0.003 & -0.27 & 0.787 & -0.025 & 0.019 \\
\hline \multicolumn{6}{|l|}{ Sunlight (low) } \\
\hline Moderate & -0.005 & -0.62 & 0.536 & -0.019 & 0.010 \\
\hline High & 0.000 & -0.04 & 0.969 & -0.020 & 0.019 \\
\hline Age (years) & 0.001 & 4.26 & 0.000 & 0.001 & 0.002 \\
\hline Pre-op CDVA (LogMAR) & -0.366 & -9.41 & 0.000 & -0.442 & -0.290 \\
\hline Pre-op SE (D) & -0.006 & -4.63 & 0.000 & -0.009 & -0.004 \\
\hline Constant & -0.079 & -4.74 & 0.000 & -0.111 & -0.046 \\
\hline
\end{tabular}

Abbreviations: CDVA, corrected distance visual acuity; El, efficiency index; SE, spherical equivalent; Pre-op, preoperative; D, diopter.

on days with lower temperature had a statistically significant better EI. Moreover, there was a significant difference for SI in eyes being treated on days with lower temperatures, thereby suggesting that lower temperatures have a positive influence on SI.

To provide a thorough analysis of the influence of independent variables within a multivariate framework, robust regression methods were applied, thereby defining EI, SI, and postoperative SE as dependent variables. The results are summarized in Tables 4-6 and Figures 1 and 2 .

The EI of eyes with refractive surgery during summer was 0.023 higher $(P=0.032)$ compared to those treated during winter, thereby indicating less efficiency (Table 4). This meant less appropriate postoperative UDVA relative to preoperative CDVA in eyes being treated during summer. Analyzed as dependent variables, different temperature levels did not significantly influence EI (Table 4).

The SI of eyes with refractive surgery during summer was slightly lower compared to that of those treated during winter, thereby resulting in no statistically significant difference (Table 5). Higher temperatures had a statistically significant $(P=0.049)$ effect on SI, as its positive coefficient indicated a negative impact on SI.

Robust regression with postoperative SE as the dependent variable did not reveal statistically significant results, whether for season, temperature, or sunlight duration.

Varying the duration of sunlight did not result in statistically significant differences for EI, SI, or postoperative SE. This was confirmed by the predictability of SE, as approximately $81 \%$ of the results were within $\pm 0.50 \mathrm{D}$ of the attempted correction (Figure 3). Lower temperatures resulted in higher predictability of SE, as $87.00 \%$ were within $\pm 0.50 \mathrm{D}$ of the attempted correction (Figure 4).

None of the coefficients on meteorological parameters or their combinations exceeded the weight of $(+/-) 0.1$. No change by more than one line on the LogMAR scale was thus obtained, as one decimal unit (0.1) represented one line on the LogMAR scale.

Table 5 Robust regression with $\mathrm{SI}$ as dependent variable

\begin{tabular}{llllr}
\hline & Coefficient & $\boldsymbol{t}$ & P-value & 95\% confidence interval \\
\hline $\begin{array}{l}\text { Season (winter) } \\
\text { Summer }\end{array}$ & -0.003 & -0.420 & 0.677 & -0.015 \\
$\begin{array}{l}\text { Temperature (low) } \\
\quad \text { Moderate }\end{array}$ & 0.010 & 1.820 & 0.069 & -0.001 \\
$\quad$ High & 0.013 & 1.970 & 0.049 & 0.000 \\
Sunlight (low) & & & & 0.010 \\
$\quad$ Moderate & -0.004 & -0.910 & 0.363 & -0.013 \\
$\quad$ High & -0.004 & -0.630 & 0.527 & -0.016 \\
Age (years) & 0.000 & 1.380 & 0.167 & 0.000 \\
Pre-op CDVA (LogMAR) & -0.306 & -13.080 & 0.000 & -0.352 \\
Pre-op SE (D) & -0.003 & -3.400 & 0.001 & -0.004 \\
Constant & -0.043 & -4.290 & 0.000 & -0.005 \\
\hline
\end{tabular}

Abbreviations: CDVA, corrected distance visual acuity; SE, spherical equivalent; SI, safety index; Pre-op, preoperative; D, diopter. 
Table 6 Robust regression with postoperative SE as dependent variable

\begin{tabular}{|c|c|c|c|c|c|}
\hline \multirow[b]{2}{*}{ Season (winter) } & \multirow[t]{2}{*}{ Coefficient } & \multirow[t]{2}{*}{$t$} & \multirow[t]{2}{*}{$P$-value } & \multicolumn{2}{|c|}{$95 \%$ confidence interval } \\
\hline & & & & & \\
\hline Summer & -0.061 & -1.120 & 0.263 & -0.167 & 0.046 \\
\hline \multicolumn{6}{|l|}{ Temperature (low) } \\
\hline Moderate & -0.002 & -0.040 & 0.972 & -0.098 & 0.094 \\
\hline High & -0.029 & -0.500 & 0.617 & -0.143 & 0.085 \\
\hline \multicolumn{6}{|l|}{ Sunlight (low) } \\
\hline Moderate & -0.073 & -1.920 & 0.055 & -0.148 & 0.002 \\
\hline High & -0.093 & -1.810 & 0.071 & -0.194 & 0.008 \\
\hline Age (years) & -0.007 & -5.070 & 0.000 & -0.009 & -0.004 \\
\hline Pre-op CDVA (LogMAR) & -0.108 & -0.540 & 0.590 & -0.503 & 0.286 \\
\hline Pre-op SE (D) & -0.009 & -1.290 & 0.197 & -0.023 & 0.005 \\
\hline Constant & 0.223 & 2.600 & 0.010 & 0.055 & 0.392 \\
\hline
\end{tabular}

Abbreviations: CDVA, corrected distance visual acuity; SE, spherical equivalent; Pre-op, preoperative; D, diopter.

\section{Discussion}

The safety and efficacy of wavefront-optimized LASIK have been demonstrated over a wide range of myopia. ${ }^{31-33}$ The current study explores the outcome of LASIK in myopic eyes with a mean preoperative SE of $-3.88 \pm 1.85 \mathrm{D}$ and the impact of temperature and sunlight duration on the refractive and visual outcomes. There has been no previous study focusing on the success of refractive surgery and its variations related to these parameters.

Our data show that eyes being treated on days with lower temperature have a statistically significant better EI and higher predictability of SE. There is a significant difference for SI in eyes being treated on days with low temperatures, thereby suggesting that low temperature has a positive influence on SI. Moreover, high temperatures have a statistically significant $(P=0.049)$ effect on SI as its positive coefficient indicates a negative impact on SI. Nevertheless, none of the coefficients

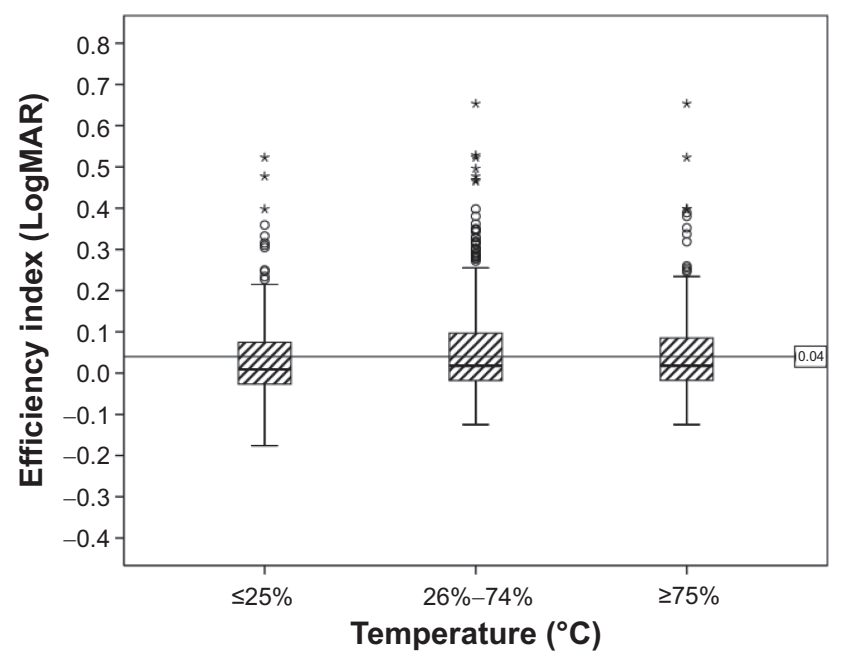

Figure I For subgroups of sunlight duration, El and SI are depicted as box plots with standard deviations.

Abbreviations: El, efficiency index; SI, safety index. on meteorological parameters or their combinations exceed the weight of (+/-) 0.1 . Therefore, no change by more than one line on the LogMAR scale was obtained, as one decimal unit (0.1) represents one line on the LogMAR scale. This was also confirmed by the mean postoperative SE of $-0.18 \pm 0.44 \mathrm{D}$ obtained at the 1-month follow-up, and the lack of significant differences within robust regression analysis with postoperative SE as the dependent variable. Accordingly, the present results indicate that there is no clinically relevant correlation between temperature and sunlight duration and the actual outcome of LASIK.

The biological influence of weather, also called biotropy, can be "health-endangering". As has been previously examined, its impact is most evident on major acute cardiovascular events. ${ }^{10}$ In addition, renal failure ${ }^{34}$ and precipitating factors in migraine ${ }^{35}$ are reportedly weather-related. A previous study ${ }^{36}$ has suggested that the cold-related

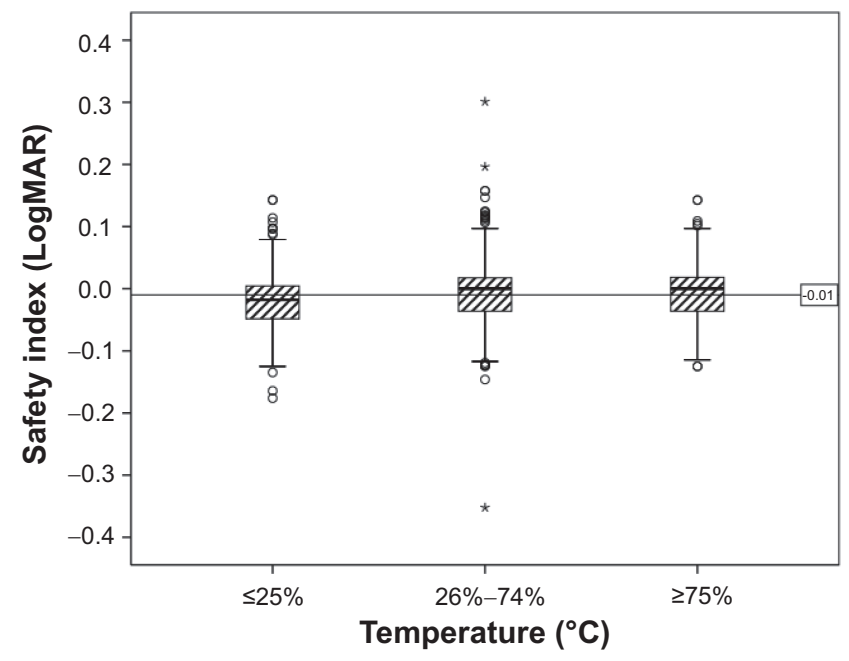

Figure 2 For subgroups of temperature, El and SI are depicted as box plots with standard deviations.

Abbreviations: El, efficiency index; SI, safety index. 

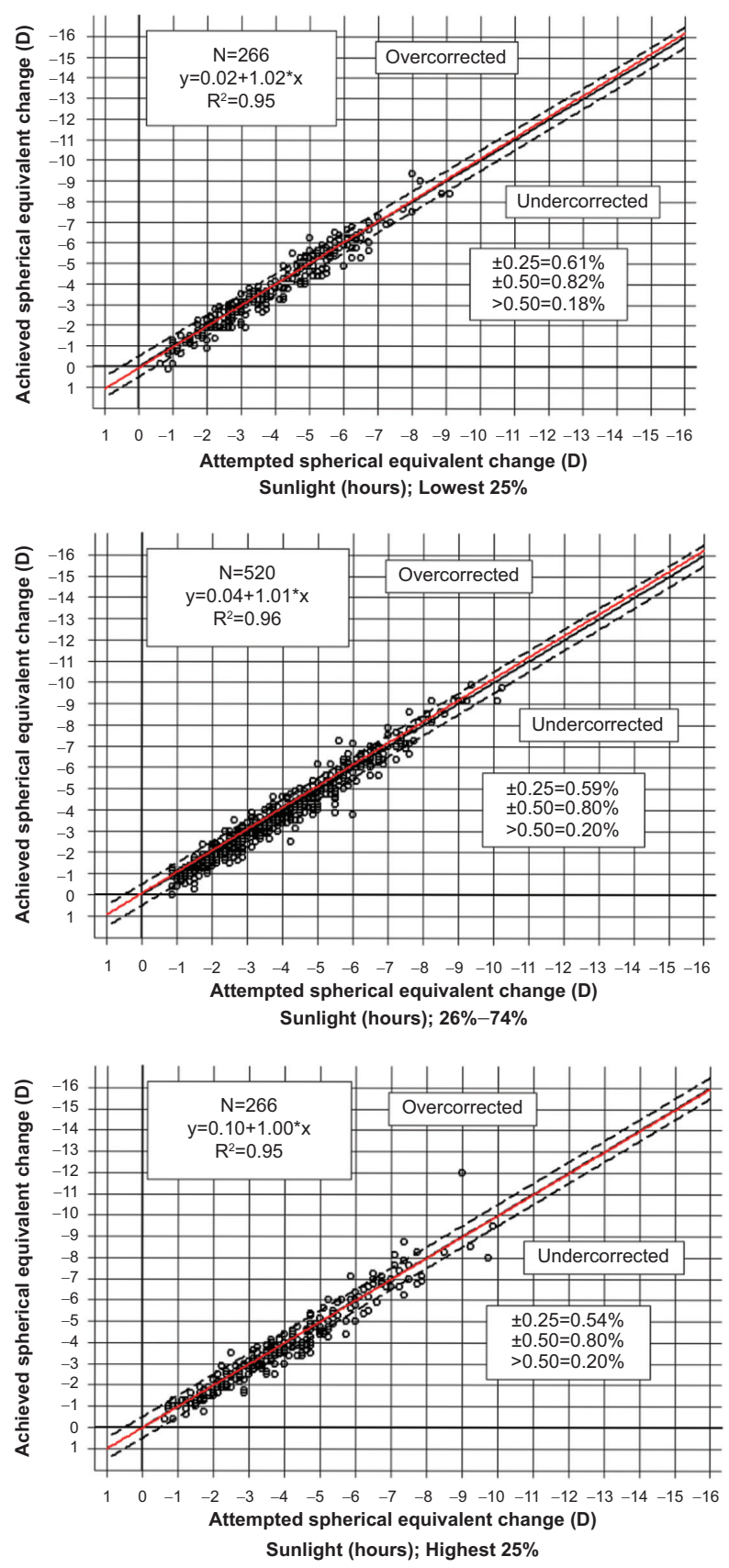

Figure 3 Attempted versus achieved SE correction at I month, displayed by subgroups of sunlight duration.

Abbreviation: SE, spherical equivalent.

increase in sympathetic nervous activity may contribute to the enhancement of platelet function, with increasing risk of thrombosis in cold weather in essential hypertension. The role of weather as a "health-endangering" factor has also been reported in the field of ophthalmology.

By applying bivariate comparison, our study reveals statistically significant differences of the effects of temperature on EI and SI. Eyes treated on days with lower temperature have a better post-LASIK outcome based on EI, SI, and postoperative SE.
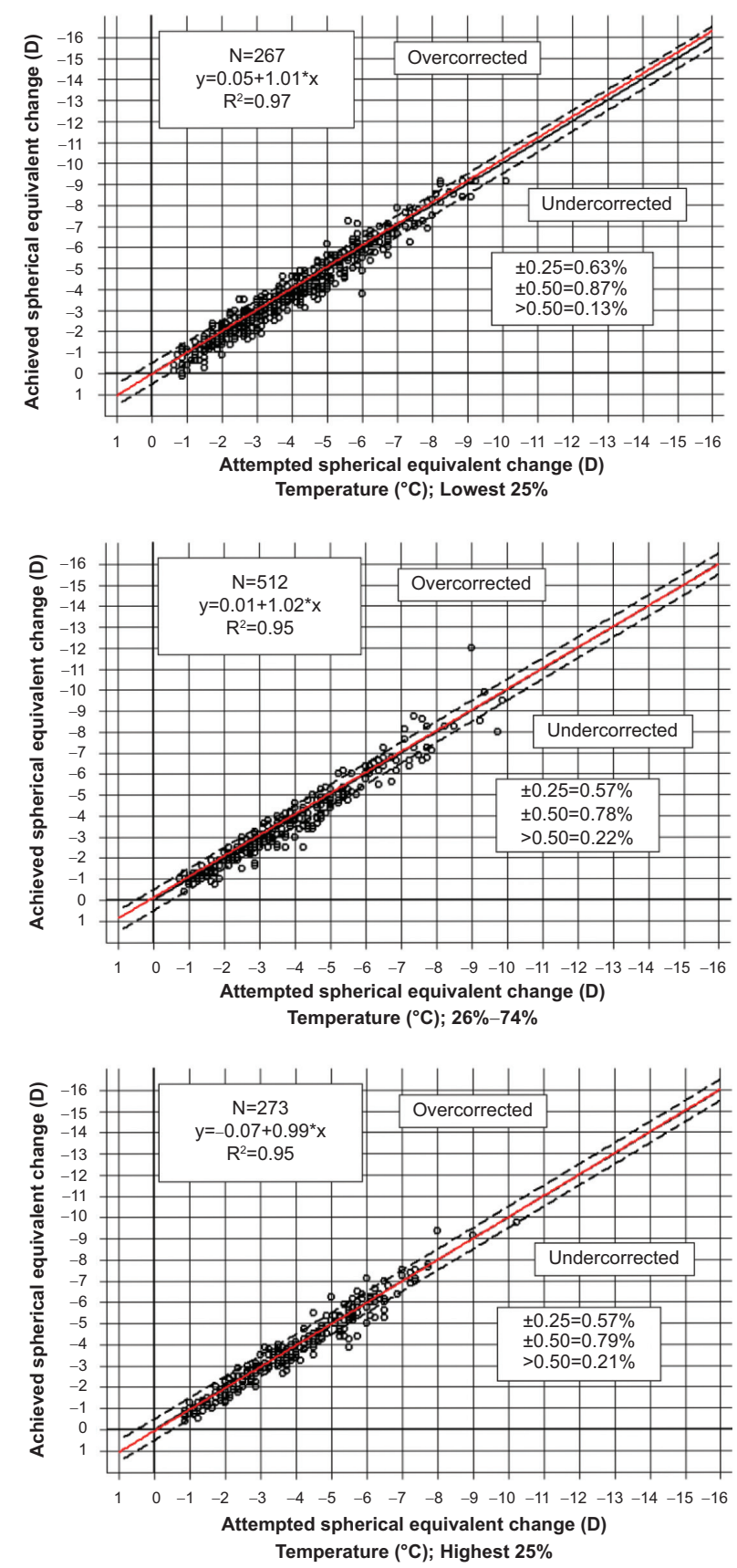

Figure 4 Attempted versus achieved SE correction at I month, displayed by subgroups of temperature.

Abbreviation: SE, spherical equivalent.

Lower temperature is usually associated with domination of a low pressure system. Low pressure systems are mostly present during the cold period of the year. Accordingly, our findings of bivariate comparison are related to uncomfortable outside conditions. The observed effects could be attributed to either the direct or indirect impact of weather conditions. The present study does not deliver details to differentiate between these theories.

Despite these findings, it is necessary to estimate the unique effects of dependent variables within a multivariate 
framework. Tables 4-6 show the results of robust regression methods with EI, SI, and postoperative SE as the dependent variables.

The EI of eyes with refractive surgery during summer is 0.023 higher $(P=0.032)$ compared to that of those treated during winter, thereby indicating less efficiency. This means less appropriate postoperative UDVA relative to preoperative CDVA in eyes being treated during summer.

Our analysis of SI as a dependent variable by robust regression methods is consistent to our findings on EI. Higher temperatures are related to less safe results. These conditions are usually present in favorable outside conditions, which are preferentially found during summer.

All meteorological data reported herein are based on hourly readings and daily summaries, recorded by the meteorological stations of the German Weather Service. These stations were located in different German cities, with each station being close to the local Care Vision Center where refractive treatments have been performed.

As most of Germany has a temperate seasonal climate with winters being mild and summers tending to be cool, we think our findings can favorably be compared to patients being treated in many countries worldwide. However, it may be difficult to compare our findings to regions with divergent climatic conditions, as this would probably be confounded by other factors such as hygiene standards, local health systems, and epidemiological factors.

Previous studies have shown convincingly good clinical results following LASIK. The data reported herein contribute to this notion as we cannot assess clinically relevant differences in outcome related to temperature or sunlight duration. This is evidenced by the lack of meteorologicalrelated changes by more than one line on the LogMAR scale. Therefore, we conclude that the refractive outcome after LASIK is independent from these meteorological parameters. However, lower outdoor temperatures seem to be connected to minimally better results. This was suggested by robust regression analysis with SI as the dependent variable (Table 5), bivariate comparison of EI (Table 3), and predictability of SE (Figure 4).

Meteorotropic reaction is a function of the intensity of the influencing factors, and of the exposure to them, as well as the individual's adaptive capability. ${ }^{9}$ Previous studies on meteorotropic reaction have usually examined the elderly population, thereby accounting for the prevalence of comorbidity and its correlation to outcome. This study mainly accounts for younger individuals with healthy eyes. We see this as an advantage in interpreting our data, as this study was initiated to analyze LASIK patients. On the other hand, weather-related reactions could perhaps be concealed for the same reasons, as our patients are not classically at high risk of meteotropism.

Of course, we cannot $100 \%$ control for the effect of the individual examiner/the set-up, but each patient was treated by the same optometrist pre- and post-operatively (which means individual examination techniques should equally influence the pre- and post-operative results). However, this is a limitation of almost all refractive studies (moreover, it is even more difficult when the study design is retrospective and a large patient pool is analyzed). Higher order aberrations were, unfortunately, not analyzed in our study (however, if altering our results, both subgroups should be influenced equally). An important implication in interpreting our data is that we actually accounted for meteorotropic reaction during the early postsurgical follow-up, which was at 1 month. Some might argue that we would have achieved better results if we addressed each patients "risk" of being outside by a prospective study addressing more factors like the influence of smoking or going walking. However, we see our methodological framework as a sound approach, as differences between individuals are hard to assess when a large patient population is analyzed. Only controlled, prospective studies can circumvent this selection bias.

To systematize the meteorological influence by single centers, previously introduced weather type clusters would have been helpful. ${ }^{9,37}$ This would have enabled us to assess a range of weather types, thus accounting better for their complexity. However, this was addressed by a multivariate analysis of parameters analyzed herein.

\section{Conclusion}

In the present study, we examined the possible role of temperature and sunlight duration on the refractive and visual outcomes of LASIK in myopic eyes.

To conclude, the results of this paper indicate that there is no clinically relevant correlation between temperature and sunlight duration and the actual outcome of LASIK.

To assess meteorotropic reactions following LASIK, further investigations should be initiated evaluating individual risk profiles, with the aim of providing the best possible visual acuity and subjective visual quality postoperatively in a stable, precise, and safe manner.

\section{Author contributions}

All authors made substantial contributions to conception and design, acquisition of data, or analysis and interpretation of 
data. All authors took part in drafting the article or revising it critically for important intellectual content and gave final approval of the version to be published.

\section{Disclosure}

The authors report no conflicts of interest in this work.

\section{References}

1. Duffey RJ, Leaming D. US trends in refractive surgery: 2004 ISRS/ AAO Survey. J Refract Surg. 2005;21(6):742-748.

2. Bielory BP, O'Brien TP. Allergic complications with laserassisted in-situ keratomileusis. Curr Opin Allergy Clin Immunol. 2011;11(5):483-491.

3. Wu HK. Astigmatism and LASIK. Curr Opin Ophthalmol. 2002;13(4): 250-255.

4. Albietz JM, McLennan SG, Lenton LM. Ocular surface management of photorefractive keratectomy and laser in situ keratomileusis. $J$ Refract Surg. 2003;19(6):636-644.

5. Johnson GJ. The environment and the eye. Eye (Lond). 2004;18(12): 1235-1250.

6. Kunst AE, Looman CW, Mackenbach JP. Outdoor air temperature and mortality in the Netherlands: a time-series analysis. Am J Epidemiol. 1993;137(3):331-341.

7. Scholander PF, Hock R, Walters V, Irving L. Adaptation to cold in arctic and tropical mammals and birds in relation to body temperature, insulation, and basal metabolic rate. Biol Bull. 1950;99(2):259-271.

8. Erikson H, Krog J, Andersen KL, Scholander PF. The critical temperature in naked man. Acta Physiol Scand. 1956;37(1):35-39.

9. Bucher K, Haase C. Meteorotropy and medical-meteorological forecasts. Experientia. 1993;49(9):759-768

10. Verberkmoes NJ, Soliman Hamad MA, Ter Woorst JF, Tan ME, Peels $\mathrm{CH}$, van Straten $\mathrm{AH}$. Impact of temperature and atmospheric pressure on the incidence of major acute cardiovascular events. Neth Heart J. 2012;20(5):193-196.

11. Sartor F, Snacken R, Demuth C, Walckiers D. Temperature, ambient ozone levels, and mortality during summer 1994, in Belgium. Environ Res. 1995; 70(2):105-113.

12. Gautam PL, Kathuria S, Chhabra S. Hot climate and perioperative outcome in elderly patients. Indian J Crit Care Med. 2011;15(2):88-95.

13. Conti S, Meli P, Minelli G, et al. Epidemiologic study of mortality during the Summer 2003 heat wave in Italy. Environ Res. 2005; 98(3):390-399.

14. Ellis FP, Nelson F, Pincus L. Mortality during heat waves in New York City July, 1972 and August and September, 1973. Environ Res. 1975;10(1):1-13.

15. Nakai S, Itoh T, Morimoto T. Deaths from heat-stroke in Japan: 1968-1994. Int J Biometeorol. 1999;43(3):124-127.

16. Basu R. High ambient temperature and mortality: a review of epidemiologic studies from 2001 to 2008. Environ Health. 2009;8:40.

17. Bouchama A, Knochel JP. Heat stroke. N Engl J Med. 2002;346(25): 1978-1988.
18. McGeehin MA, Mirabelli M. The potential impacts of climate variability and change on temperature-related morbidity and mortality in the United States. Environ Health Perspect. 2001;109 Suppl 2:185-189.

19. Semenza JC, McCullough JE, Flanders WD, McGeehin MA, Lumpkin JR. Excess hospital admissions during the July 1995 heat wave in Chicago. Am J Prev Med. 1999;16(4):269-277.

20. Semenza JC, Rubin CH, Falter KH, et al. Heat-related deaths during the July 1995 heat wave in Chicago. N Engl J Med. 1996;335(2):84-90.

21. Ellis FP, Nelson F. Mortality in the elderly in a heat wave in New York City, August 1975. Environ Res. 1978;15(3):504-512.

22. Ellis FP. Mortality from heat illness and heat-aggravated illness in the United States. Environ Res. 1972;5(1):1-58.

23. Benouaich V, Soler P, Gourraud PA, Lopez S, Rousseau H, Marcheix B. Impact of meteorological conditions on the occurrence of acute type A aortic dissections. Interact Cardiovasc Thorac Surg. 2010;10(3):403-406.

24. Coroneo M. Ultraviolet radiation and the anterior eye. Eye Contact Lens. 2011;37(4):214-224.

25. Chalam KV, Khetpal V, Rusovici R, Balaiya S. A review: role of ultraviolet radiation in age-related macular degeneration. Eye Contact Lens. 2011;37(4):225-232.

26. Seider MI, McLeod SD, Porco TC, Schallhorn SC. The effect of procedure room temperature and humidity on LASIK outcomes. Ophthalmology. 2013;120:2204-2208.

27. Walter KA, Stevenson AW. Effect of environmental factors on myopic LASIK enhancement rates. JRS. 2004;30:798-803.

28. Dupps WJ Jr, Kohnen T, Mamalis N, et al. Standardized graphs and terms for refractive surgery results. J Cataract Refract Surg. 2011; 37(1):1-3.

29. Mrochen M, Donitzky C, Wullner C, Loffler J. Wavefront-optimized ablation profiles: theoretical background. J Cataract Refract Surg. 2004; 30(4):775-785.

30. Frings A, Katz T, Richard G, Druchkiv V, Linke SJ. Efficacy and predictability of laser in situ keratomileusis for low astigmatism of 0.75 diopter or less. J Cataract Refract Surg. 2013;39:366-377.

31. Aizawa D, Shimizu K, Komatsu M, et al. Clinical outcomes of wavefront-guided laser in situ keratomileusis: 6-month follow-up. $J$ Cataract Refract Surg. 2003;29(8):1507-1513.

32. Helmy SA, Salah A, Badawy TT, Sidky AN. Photorefractive keratectomy and laser in situ keratomileusis for myopia between 6.00 and 10.00 diopters. J Refract Surg. 1996;12(3):417-421.

33. Salah T, Waring GO 3rd, el-Maghraby A, Moadel K, Grimm SB. Excimer laser in-situ keratomileusis (LASIK) under a corneal flap for myopia of 2 to 20 D. Trans Am Ophthalmol Soc. 1995;93:163-183; discussion 184-190.

34. Semenza JC. Acute renal failure during heat waves. Am J Prev Med. 1999;17(1):97.

35. Robbins L. Precipitating factors in migraine: a retrospective review of 494 patients. Headache. 1994;34(4):214-216.

36. Kawahara J, Sano H, Fukuzaki H, Saito K, Hirouchi H. Acute effects of exposure to cold on blood pressure, platelet function and sympathetic nervous activity in humans. Am J Hypertens. 1989;2(9):724-726.

37. Danielides V, Patrikakos G, Nousia CS, et al. Weather conditions and Bell's palsy: five-year study and review of the literature. BMC Neurol. 2001;18;1:7.
Clinical Ophthalmology

\section{Publish your work in this journal}

Clinical Ophthalmology is an international, peer-reviewed journal covering all subspecialties within ophthalmology. Key topics include: Optometry; Visual science; Pharmacology and drug therapy in eye diseases; Basic Sciences; Primary and Secondary eye care; Patien Safety and Quality of Care Improvements. This journal is indexed on Submit your manuscript here: http://www.dovepress.com/clinical-ophthalmology-journal

\section{Dovepress}

PubMed Central and CAS, and is the official journal of The Society of Clinical Ophthalmology (SCO). The manuscript management system is completely online and includes a very quick and fair peer-review system, which is all easy to use. Visit http://www.dovepress.com/ testimonials.php to read real quotes from published authors. 